\title{
Single-site laparoscopic treatment of pathological intussusception secondary to heterotopic pancreas in an 11-month old infant
}

Yulei Jing

Wuxi Children's Hospital

Dafeng Wang

Wuxi Children's Hospital

Xiaomin Zhu

Wuxi Children's Hospital

Yijin Cai

Wuxi Children's Hospital

Xia li

Wuxi People's Hospital

Yingzuo Shi ( $\nabla$ yz_shi93222@126.com )

Wuxi Children's Hospital https://orcid.org/0000-0003-3956-9264

\section{Research Article}

Keywords: Heterotopic pancreas, Pathological intussusception, Single-site laparoscopic

Posted Date: May 24th, 2021

DOI: https://doi.org/10.21203/rs.3.rs-544770/v1

License: (c) (1) This work is licensed under a Creative Commons Attribution 4.0 International License.

Read Full License 


\section{Abstract}

Background: Intussusception in children is mostly idiopathic, while intestinal intussusception in infancy is uncommon. Specially, intussusception caused by isolated ileal heterotopic pancreas, the abnormal localization of a well-differentiated pancreatic tissue in the ileal serosa, is relatively rare. Early recurrence of intussusception would suggest the presence of pathological lead point and the possibility of surgical exploration.

Case presentation: An 11-month-old boy, diagnosed with recurrent intussusception caused by ileal heterotopic pancreas, was admitted to our hospital. After admission, the baby was resuscitated with normal saline and received air edema twice, but both failed. Given the presence of pathological intussusception, the boy was sent to operating theater and received a single-site laparoscopically assisted surgery. The patient recovered successfully and got a satisfactory cosmetic result.

Conclusions: Due to its minimally invasive and diagnostic advantages, laparoscopy proves to be a safe and attractive alternative, especially for emergency patient with stable hemodynamics but no definite radiological diagnosis. Meanwhile, we emphasize the importance of paying essential attention to the condition that recurrent intussusception of extreme age should always be taken into consideration.

\section{Background}

Intussusception, mostly idiopathic in pediatric case[1], is the leading cause of intestinal obstruction in children. A small proportion of intussusception is caused by pathological lead point, accounting for about $2-12 \%$ of pediatric cases[2], with Meckel's diverticulum as the most common cause of pathological intussusception[2, 3].

Heterotopic pancreas (HP), defined as a well-differentiated pancreatic tissue, is anatomically separate from the pancreas and has no vascular or ductal continuity with the organ's main body. Although, small intestinal heterotopic pancreatic tissue is not uncommon, pediatric cases of isolated heterotopic pancreatic tissue in the ileum causing intussusception have seldom been reported[4].

Early recurrence of intussusception would indicate the presence of an aberrant lead point, indicating the possibility of surgical exploration[2]. Here, we report a pediatric case of recurrent intussusception caused by ileal heterotopic pancreas. This case was treated by single-site laparoscopy and a satisfactory cosmetic result was achieved after surgery. Meanwhile, the necessity of essential attention to such condition and the clinical significance of this rarity are concerned.

\section{Case Presentation}

An 11-month-old boy, presented with 3-hour history of paroxysmal crying, non-bilious vomiting and nonbloody diarrhea, was diagnosed with intussusception in the right lower quadrant by abdominal ultrasound examination and admitted to our hospital (Fig. 1a). Three months prior this admission, the 
boy had a similar history of intussusception that occurred twice within 14 hours and was successfully reduced by air enema(Fig. 1b). After admission, the boy was resuscitated with normal saline and received air edema twice, but both failed (Fig. 3a). Although the presence of pathological lead point was suspected,no evidence of radiological or ultrasound examination confirmed. Given the clinical condition, the boy was sent to the operating room for laparoscopic exploration 7 hours after admission. A $20-\mathrm{cm}-$ long ileo-ileo-colic intussusceptum was noticed in the ascending colon. Then complete reduction of the intussusception was achieved laparoscopically. No serosal tears or bowel perforation occurred. Fifty centimeters proximal to the ileocecal valve, an abnormal mass, presented in the form of small yellowish nodule with a diameter of $1 \mathrm{~cm}$, was noted under the intestine serosa of the contralateral margin of mesentery, considering to have acted as the pathological lead point for the intussusception ( Fig. 2a). A minimal extension of the umbilical incision to about $3 \mathrm{~cm}$ was made to allow for further operation. This mass, along with $0.5 \mathrm{~cm}$ of small bowel both proximal and distal to the mass were resected and a primary single layer handsewn longitudinal anastomosis was performed. The rest small intestine from ligament of Treitz to the ileo-ceal valve was examined to be healthy.

An isolated heterotopic pancreatic tissue within the ileum serosa was demonstrated by pathological examination (Fig. 2b. Figure 2c).

The patient recovered successfully, restored a liquid diet on the 4th day and was eventfully discharged on the 6th day after operation (Fig. 3b).

\section{Discussion And Conclusions}

Intussusception, the second universal etiology of abdominal emergency in children, is the most common cause of intestinal obstruction in young infants[5,6]. Most cases of intussusception occur between 3 months and 2 years of age, with the highest incidence between the fifth and ninth month of life. The ileocolic intussusception is the predominant type in pediatric cases, with most of them idiopathic[7].

Most ileocolic intussusception can be successfully reduced by hydrostatic or air enema, while intestinal intussusception is relatively more difficult to be reduced by normal approaches and often requires surgical treatment.

Heterotopic pancreas refers to the abnormally localized, well-differentiated pancreatic tissue which lacks the anatomical and vascular continuity with the primary pancreatic body. Intestinal intussusception secondary to HP has been reported rarely in relating studies[8-12]. In fact, isolate HP is extremely rare, accounting for a proportion of $0.5 \%$ of upper abdominal operations.

The true incidence and prevalence are not well known and may even be underestimated as asymptomatic individuals accounting for up to $85 \%[7]$, hence most cases are found incidentally upon performing another procedure[13-15]. Heterotopic pancreas is usually found in the upper digestive tract, surrounding the main body of the pancreas, most commonly the stomach. 
Recurrent intussusception is relatively commonplace, with the rate of recurrence reported to be about 8$15 \%[16,17]$. For children of extreme age[4] or those with recurrent intussusception, the presence of pathological lead points must be in consideration[18].

Since the preoperative diagnosis of symptomatic HP was difficult, many cases were either misdiagnosed or missed[19,20]. To date, no reliable laboratory marker for the judgement of HP tissue was found[21, 14]. Generally, CT, capsule endoscopy and double-balloon enteroscopy were regarded as effective methods for preoperative examination[21]. Nevertheless, despite these advanced diagnostic tools, clinical symptoms, imaging and endoscopic features are non-specific and often not sufficient to make a definitive diagnosis[11]. Therefore, the preoperative diagnosis of a heterotopic pancreas remains challenging especially in pediatric emergency obstruction cases, and the definitive diagnosis still relies on the postoperative histopathological examination.

Occasionally, heterotopic tissue may undergo metaplastic changes that lead to the development of malignancy in adulthood[22, 23]; even though exceedingly rare, malignant neoplasms arising from HP have also been reported in children[24-26]. Up to now,no clear criteria is established for the management of HP found coincidentally during surgery. If the patient's condition permits and no additional risk is added, resection should be taken into account because of the risk of later clinical problems, including intussusception, intestinal obstruction, and mucosal hemorrhage from ulceration. Some suggestions or principles are as follows[27]:1. prophylactic resection of HP does not conflict with scheduled surgery plan or increase the risk or extend the scope of the surgery. 2. The HP with a diameter of $1.5 \mathrm{~cm}$ should be surgically removed for the increasing possibility of severe complications. 3. HP that locates at the ileum or the Meckel's diverticulum should be removed, as it can act as pathological lead point of intussusception.

In this report, we have performed laparoscopic reduction of intussusception and the procedure is promising as an alternative for the management of intussusception. When resection is required, a laparoscopy-assisted technique can be performed with minimal extension of the umbilical wound. In addition, this case highlights the importance of recognizing the presence of a possible lead point after reduction of the intussusception and a careful inspection is necessary during the operation.

Overall, due to its general advantages and diagnostic benefits, laparoscopy is increasing proved to be a safe and attractive option, especially for emergency patient with stable hemodynamics but no definite radiological diagnosis.

\section{Declarations}

\section{Acknowledgements}

Not applicable.

\section{Authors' contributions}


All authors made substantial contributions to the conception and design of this work. All authors were involved in drafting, reviewing and approved the final version for submission.

\section{Funding}

The authors acknowledge support from the Young project of Wuxi health committee (Grant No. Q201604), the Top Talents Project of Wuxi Taihu Lake Talent plan (Grant No. HB2020084) and the Science and Technology Development Fund Project of Nanjing Medical University (Grant No.

NMUB2020301).

\section{Availability of data and materials}

No datasets were generated or analyzed during the current study.

\section{Ethics approval and consent to participate}

Not applicable.

\section{Consent for publication}

Written informed consent was obtained from the patient's parents for the publication of this case report.

\section{Competing interests}

The authors declare that they have no competing interests.

\section{Author details}

a Department of Pediatric Surgery, The Affiliated Wuxi Children's Hospital of Nanjing Medical University, Wuxi, Jiangsu, 214023, RP China

b Department of Pathology, The Affiliated Wuxi People's Hospital of Nanjing Medical University, Wuxi, Jiangsu, 214023, RP China

* Correspondence to: Yingzuo Shi, Department of Pediatric Surgery, The Affiliated Wuxi Children's Hospital of Nanjing Medical University, Wuxi, Jiangsu, 214023, RP China.

E-mail addresses:954100253@qq.com.

1 Contributed equally.

\section{Abbreviations}

HP: heterotopic pancreas 


\section{References}

1. Abel R, Keen CE, Bingham JB, Maynard J, Agrawal MR, Ramachandra S. Heterotopic pancreas as lead point in intussusception: new variant of vitellointestinal tract malformation. Pediatr Dev Pathol. 1999;2(4):367-70.

2. Ong NT, Beasley SW. The leadpoint in intussusception. J Pediatr Surg. 1990;25(6):640-3.

3. Stringer MD, Pablot SM, Brereton RJ. Paediatric intussusception. Br J Surg. 1992;79(9):867-76.

4. Hamada Y, Yonekura Y, Tanano A, Takada K, Kato Y, Sato M et al. Isolated heterotopic pancreas causing intussusception. Eur J Pediatr Surg. 2000;10(3):197-200.

5. Waseem M, Rosenberg HK. Intussusception. Pediatr Emerg Care. 2008;24(11):793-800.

6. Applegate KE. Intussusception in children: evidence-based diagnosis and treatment. Pediatr Radiol. 2009;39 Suppl 2:S140-3.

7. Seifarth FG, Ryan ML, Triana J, Knight CG. Diagnosis and laparoscopic treatment of ileoileal intussusception secondary to heterotopic pancreas in an infant: case report and review of the literature. J Pediatr Surg. 2011;46(2):e33-6.

8. Jacobz A, Nawaz A, Matta H, Al SA. Intussusception secondary to isolated heterotopic pancreas of the ileum: case report and review of the literature. Ann Saudi Med. 2002;22(3-4):213-5.

9. Gurbulak B, Kabul E, Dural C, Citlak G, Yanar H, Gulluoglu M et al. Heterotopic pancreas as a leading point for small-bowel intussusception in a pregnant woman. JOP. 2007;8(5):584-7.

10. Chuang MT, Tsai KB, Ma CJ, Hsieh TJ. Ileoileal intussusception due to ileal ectopic pancreas with abundant fat tissue mimicking lipoma. Am J Surg. 2010;200(2):e25-7.

11. Singh S, Batra A, Sangwaiya A, Marwah N, Rattan K, Sen R. Heterotopic pancreas presenting as ileoileal intussusception. J Surg Case Rep. 2012;2012(9):13.

12. Monier A, Awad A, Szmigielski W, Muneer M, Alrashid A, Darweesh A et al. Heterotopic pancreas: a rare cause of ileo-ileal intussusception. Pol J Radiol. 2014;79:349-51.

13. Zhang Y, Sun X, Gold JS, Sun Q, Lv Y, Li Q et al. Heterotopic pancreas: a clinicopathological study of 184 cases from a single high-volume medical center in China. Hum Pathol. 2016;55:135-42.

14. Rezvani M, Menias C, Sandrasegaran K, Olpin JD, Elsayes KM, Shaaban AM. Heterotopic Pancreas: Histopathologic Features, Imaging Findings, and Complications. Radiographics. 2017;37(2):484-99.

15. Betzler A, Mees ST, Pump J, Scholch S, Zimmermann C, Aust DE et al. Clinical impact of duodenal pancreatic heterotopia - Is there a need for surgical treatment? Bmc Surg. 2017;17(1):53.

16. Fecteau A, Flageole H, Nguyen LT, Laberge JM, Shaw KS, Guttman FM. Recurrent intussusception: safe use of hydrostatic enema. J Pediatr Surg. 1996;31(6):859-61.

17. Niramis R, Watanatittan S, Kruatrachue A, Anuntkosol M, Buranakitjaroen V, Rattanasuwan $T$ et al. Management of recurrent intussusception: nonoperative or operative reduction? J Pediatr Surg. 2010;45(11):2175-80. 
18. Daneman A, Alton DJ, Lobo E, Gravett J, Kim P, Ein SH. Patterns of recurrence of intussusception in children: a 17-year review. Pediatr Radiol. 1998;28(12):913-9.

19. Amr MA, Polites SF, Alzghari M, Onkendi EO, Grotz TE, Zielinski MD. Intussusception in adults and the role of evolving computed tomography technology. Am J Surg. 2015;209(3):580-3.

20. Honjo H, Mike M, Kusanagi H, Kano N. Adult intussusception: a retrospective review. World J Surg. 2015;39(1):134-8.

21. Kim DU, Lubner MG, Mellnick VM, Joshi G, Pickhardt PJ. Heterotopic pancreatic rests: imaging features, complications, and unifying concepts. Abdom Radiol (NY). 2017;42(1):216-25.

22. Emerson L, Layfield LJ, Rohr LR, Dayton MT. Adenocarcinoma arising in association with gastric heterotopic pancreas: A case report and review of the literature. J Surg Oncol. 2004;87(1):53-7.

23. Fukino N, Oida T, Mimatsu K, Kuboi Y, Kida K. Adenocarcinoma arising from heterotopic pancreas at the third portion of the duodenum. World J Gastroenterol. 2015;21(13):4082-8.

24. Yang $X$, Wang X. Imaging findings of pancreatoblastoma in 4 children including a case of ectopic pancreatoblastoma. Pediatr Radiol. 2010;40(10):1609-14.

25. Yang ZH, Gao JB, Yue SW, Yang XH, Guo H. Synchronous ectopic pancreatoblastoma in a child: a case report. J Korean Med Sci. 2011;26(6):832-5.

26. Sharma S, Agarwal S, Nagendla MK, Gupta DK. Omental acinar cell carcinoma of pancreatic origin in a child: a clinicopathological rarity. Pediatr Surg Int. 2016;32(3):307-11.

27. Wu HZ, Wu XJ, Feng JX, et al. Surgical treatment of pediatric heterotopic pancreas detected accidentally during laparotomy. Chin J pediatr Surg. 2017;38(3):207-10.

\section{Figures}
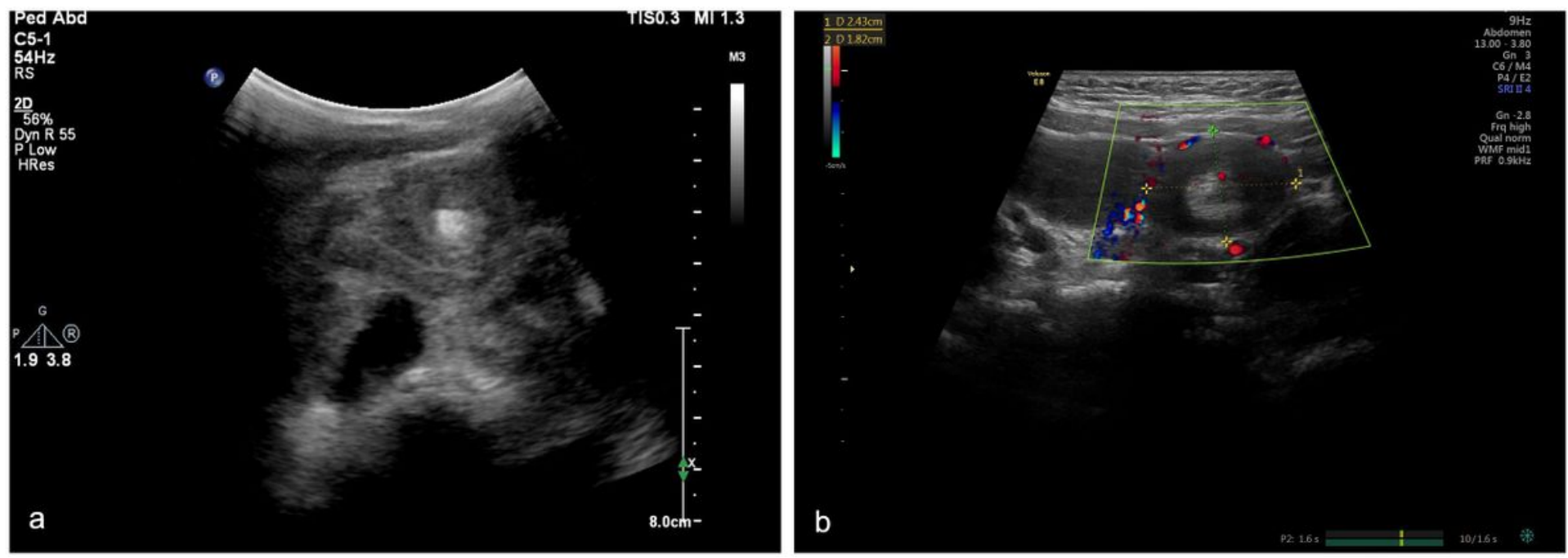

\section{Figure 1}


Abdominal ultrasound examination showed the target/doughnut sign, seen on transvers views. A: Target loop was seen in the right lower abdomen by ultrasound examination before admission. B: Ultrasound examination confirmed the presence of target loop in the left abdomen 3months prior this admission.
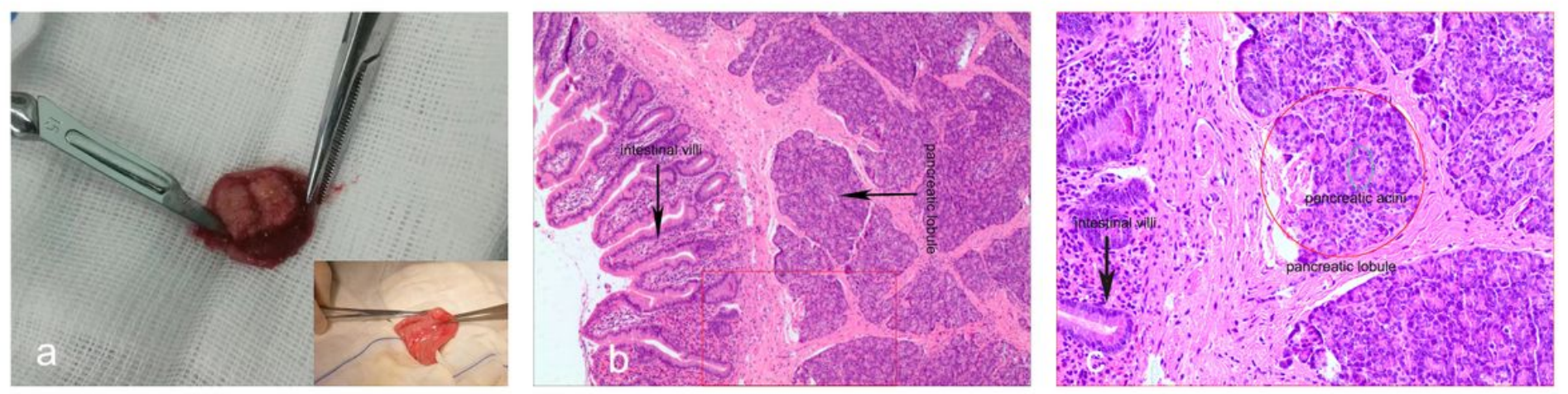

\section{Figure 2}

Surgical and pathological findings confirmed the diagnosis of heterotopic pancreas. A: One small yellowish nodule with a diameter of $1 \mathrm{~cm}$ located under the intestine serosa of the contralateral margin of mesentery. B: Pathological examination confirmed the concurrence of intestinal villi and pancreatic tissue. C: Enlargement of the small image in Figure B in the red small box.
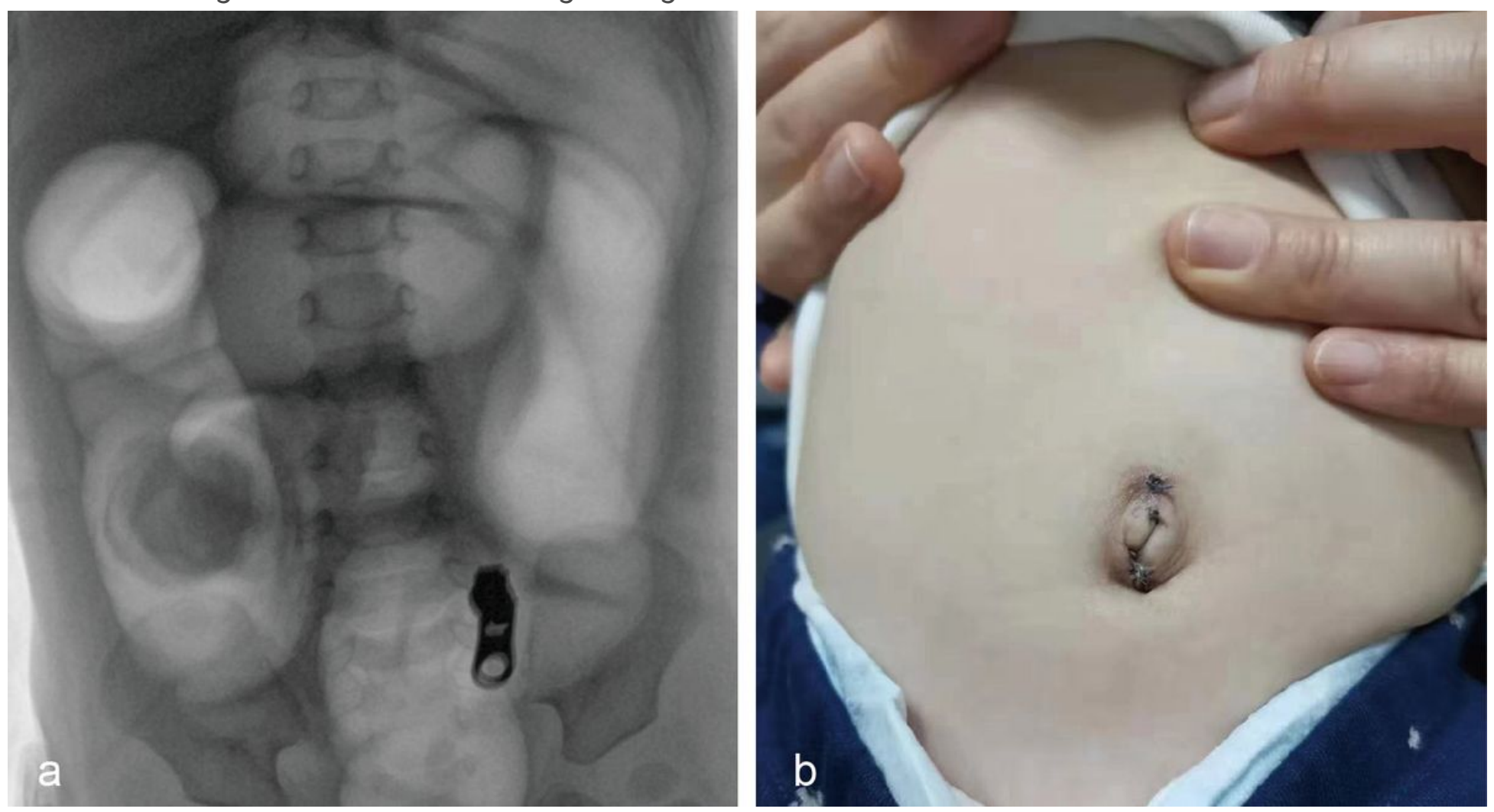

\section{Figure 3}

Radiographic picture of air enema and postoperative follow-up image. A: The intussusception could not be reduced and the intussusceptum was obstructed in the ileocecal junction. B: A satisfactory cosmetic 
result was achieved after surgery. 